\title{
Perovskite solar cells for roll-to-roll fabrication
}

\author{
Ashraf Uddin*, Md Arafat Mahmud, Naveen Kumar Elumalai, Dian Wang, Mushfika Baishakhi Upama, \\ Matthew Wright, Kah Howe Chan, Faiazul Haque, and Cheng Xu \\ School of Photovoltaics and Renewable Energy Engineering, University of New South Wales, Sydney 2052, Australia
}

Received: 5 January 2017 / Received in final form: 23 June 2017 / Accepted: 27 July 2017

\begin{abstract}
Perovskite solar cell (PSCs) is considered as the game changer in emerging photovoltaics technology. The highest certified efficiency is $22 \%$ with high temperature processed $\left(\sim 500^{\circ} \mathrm{C}\right) \mathrm{TiO}_{2}$ based electron transport layer (ETL). High temperature process is a rudimentary hindrance towards roll-to-roll processing of PSCs on flexible substrates. Low temperature solution process $\left(<150^{\circ} \mathrm{C}\right) \mathrm{ZnO}$ based ETL is one of the most promising candidate for large scale roll-to-roll fabrication of cells as it has nearly identical electron affinity $(4.2 \mathrm{eV}) \mathrm{of} \mathrm{TiO}_{2}$. The mixed organic perovskite $\left(\mathrm{MA}_{0.6} \mathrm{FA}_{0.4} \mathrm{PbI}_{3}\right)$ devices with $\mathrm{Al}$ doped $\mathrm{ZnO}$ (AZO) ETL demonstrate average cell efficiency over $16 \%$, which is the highest ever reported efficiency for this device configuration. The energy level alignment and related interfacial charge transport dynamics at the interface of $\mathrm{ZnO}$ and perovskite films and the adjacent charge transport layers are investigated. Significantly improved device stability, hysteresis free device photocurrent have been observed in $\mathrm{MA}_{0.6} \mathrm{FA}_{0.4} \mathrm{PbI}_{3}$ cells. A systematic electrochemical impedance spectroscopy, frequency dependent capacitance spectra, surface morphology and topography characterization have been conducted to understand the role of interfacial electronic properties between perovskite and neighbouring layers in perovskite device. A standardized degradation study, interfacial electronic property and capacitive spectra analysis of aged device, have been measured to understand the enhanced device stability in mixed $\mathrm{MA}_{0.6} \mathrm{FA}_{0.4} \mathrm{PbI}_{3}$ cells. Slow perovskite material decomposition rate and augmented device lifetime with AZO based devices have been found to be correlated with the more hydrophobic and acidic nature of AZO surface compared to pristine $\mathrm{ZnO}$ film.
\end{abstract}

\section{Introduction}

Organic-inorganic hybrid solar cells using metal-halide perovskites such as methylammonium lead iodide $\left(\mathrm{CH}_{3} \mathrm{NH}_{3} \mathrm{PbI}_{3}\right)$ as light harvesters exhibit several appealing features such as high optical cross section, excellent ambipolar charge transport, small exciton binding energy, tunable band gaps, and low-cost fabrication [1]. Importantly, the $\mathrm{CH}_{3} \mathrm{NH}_{3} \mathrm{PbI}_{3}$ perovskite solar cells (PSCs) are solution-processable, which is beneficial to inexpensive largescale commercialization. Over the past few years several groups have reported high power conversion efficiencies (PCEs) up to $22 \%$ raising expectations for PSCs to be deployed on a large scale along with conventional silicon based solar cells [2]. The highest efficient cells $22 \%$ was fabricated with high temperature processed $\left(\sim 500^{\circ} \mathrm{C}\right) \mathrm{TiO}_{2}$ based electron transport layer (ETL). It is very important to develop a low temperature process technology $\left(<150{ }^{\circ} \mathrm{C}\right)$ for the roll-to-roll fabrication of perovskite cell on flexible substrate.

\footnotetext{
* e-mail: a.uddin@unsw.edu. au
}

Zinc oxide $(\mathrm{ZnO})$ is known to have an electron mobility that is substantially higher than that of $\mathrm{TiO}_{2}$, which makes it an ideal choice for an electron-selective contact. The $\mathrm{ZnO}$ nanoparticle layer can be deposited easily by spin coating and requires no heating or sintering step, which makes it ideal for deposition on thermally sensitive substrates. The solution-processing of the $\mathrm{ZnO}$ layer is simple, economical and proceeds at room temperature, which gives it important advantages over other cell designs that use mesoporous scaffolds or vapour-phase deposition techniques [3]. The thickness of $\mathrm{ZnO}$ film can be varied systematically by repeating the spin-coating process several times. However, alkaline $\mathrm{ZnO}$ surface helps to produce methyl ammonium ion $\left(\mathrm{CH}_{3} \mathrm{NH}_{3}{ }^{+}\right)$when the perovskite film grown on $\mathrm{ZnO}$ and annealed at temperature around $100{ }^{\circ} \mathrm{C}[4]$. The perovskite crystal structure on $\mathrm{ZnO}$ ETL undergoes thermal decomposition even at temperature $100^{\circ} \mathrm{C}$ annealing. This thermal instability of perovskite film on $\mathrm{ZnO}$ ETL is a major bottleneck towards practical application of PSC under sunlight.

The chemical formula of mixed organic cation PSCs can be expressed as: $\mathrm{ABX}_{3}$, where $\mathrm{A}$ stands for a combination of methyl ammonium (MA) $\left[\mathrm{CH}_{3} \mathrm{NH}_{3}{ }^{+}\right]$and formamidinium 
(FA) $\left[\mathrm{HN}=\mathrm{CHNH}_{3}{ }^{+}\right]$organic cations, $\mathrm{B}$ denotes a divalent metal ion (usually $\mathrm{Pb}$ or $\mathrm{Sn}$ ) and $\mathrm{X}$ symbolizes individual halogen element ( $\mathrm{I}$ or $\mathrm{Br}$ or $\mathrm{Cl}$ ). The high ionic radius (1.9$2.2 \AA$ ) of the formamidinium cation is bigger than that of methyl ammonium ion (1.8 $\AA$ ) [5]. The formamidinium based perovskite material has a higher perovskite tolerance factor because of their bigger ionic radius which provides much better structural stability [6]. However, the open circuit voltage $\left(V_{\mathrm{OC}}\right)$ is relatively low in such a pristine formamidinium perovskite device resulting in a relatively lower device performance compared to that with methyl ammonium lead triiodide perovskite based PSCs [7]. The optimum trade-off between extended absorption and suppressed $V_{\mathrm{OC}}$, the concept of mixed organic cation based perovskite has come into effect which tunes the perovskite bandgap by incorporating both the methylammonium and formamidinium organic cations in a single $\mathrm{ABX}_{3}$ crystal structure [8].

Here we have demonstrated significance is achieved in mixed organic cation based planar perovskite $\left(\mathrm{MA}_{0.6} \mathrm{FA}_{0.4} \mathrm{PbI}_{3}\right)$ devices with low temperature $\left(<150^{\circ} \mathrm{C}\right)$ solution processed AZO thin films as ETL using sol-gel technique. The fabricated perovskite device exhibited high PCE of over $16 \%$ and device stability $>570 \mathrm{~h}$. Present work is also to demonstrate the in-depth analysis into the charge transfer characteristics at the interface between mixed organic cation perovskite layer and adjacent charge selective interlayer (AZO). An elaborate surface morphology and surface topography measurements are also carried out to probe into the superior performance/stability of the AZO based devices. A month-long, systematic degradation study was performed to confirm the superior lifetime of $\mathrm{MA}_{0.6} \mathrm{FA}_{0.4} \mathrm{PbI}_{3} /$ AZO based devices corroborated by the extensive analysis of electronic parameters like interfacial contact resistance, recombination resistance, flat-band potential and low frequency regime interfacial capacitance (electrode polarization) of both the fresh and aged devices.

\section{Methodology}

Patterned ITO/glass substrates were washed with Hellmanex III soap, DI water, acetone and isopropanol with duration of $10 \mathrm{~min}$ each. For ZnO ETL, 0.48 M sol-gel ZnO precursor solution was prepared by dissolving zinc acetate dehydrate $\left(\mathrm{Zn}\left(\mathrm{CH}_{3} \mathrm{COO}\right)_{2} \cdot 2 \mathrm{H}_{2} \mathrm{O}\right.$, Sigma-Aldrich, >99.0\%) in 2-methoxyethanol $\left(\mathrm{CH}_{3} \mathrm{OCH}_{2} \mathrm{CH}_{2} \mathrm{OH}\right.$, Sigma-Aldrich, $99.8 \%$, anhydrous) with an additive ethanolamine $\left(\mathrm{NH}_{2} \mathrm{CH}_{2} \mathrm{CH}_{2} \mathrm{OH}\right.$, Sigma-Aldrich, $\left.>99.5 \%\right)$ by stirring for 24 h. For AZO ETL, a $0.05 \mathrm{M}$ aluminum nitrate nonahydrate $\left(\mathrm{Al}\left(\mathrm{NO}_{3}\right)_{3} \cdot 9 \mathrm{H}_{2} \mathrm{O}\right.$, Sigma-Aldrich) solution in 2-methoxyethanol was prepared and stirred for $1 \mathrm{~h}$ at $80^{\circ} \mathrm{C}$. A $15 \mathrm{wt} \%$ AZO precursor solution was prepared by mixing the as prepared aluminum nitrate nonahydrate solution with solgel $\mathrm{ZnO}$ precursor solution in required weight ratio. Both the sol-gel $\mathrm{ZnO}$ and $\mathrm{AZO}$ precursor solutions were spin coated on ITO/glass substrate at $4000 \mathrm{rpm}$ for $60 \mathrm{~s}$ and then annealed on a hotplate at $140^{\circ} \mathrm{C}$ for half an hour. $1 \mathrm{M} \mathrm{PbI}_{2}$ solution in DMF ( $N, N$-dimethylformamide, Sigma-Aldrich, anhydrous) with $120 \mathrm{~mL}$ 4-TBP (4-tert-butylpyridine, Sigma-
Aldrich) was prepared at a temperature of $70^{\circ} \mathrm{C}$. The $\mathrm{PbI}_{2}$ solution was spin cast on $\mathrm{ZnO} / \mathrm{AZO}$ coated substrate at $3000 \mathrm{rpm}$ for $30 \mathrm{~s}$. Before spin coating, both the substrates and the solution were kept at $70^{\circ} \mathrm{C}$. Then the substrates were annealed at $100^{\circ} \mathrm{C}$ for $1 \mathrm{~h}$ and then dipped in a 2-propanol solution having a total iodide concentration of $0.0628 \mathrm{M}$ with the mole fraction of $\mathrm{CH}_{3} \mathrm{NH}_{3} \mathrm{I}$ (MAI) and $\mathrm{HN}=\mathrm{CHNH}_{3} \mathrm{I}$ (FAI) to be 0.6 and 0.4 , respectively. The devices were annealed for $10 \mathrm{~min}$ at $75^{\circ} \mathrm{C}$ after the dipping. For HTL, $73.3 \mathrm{mg} \mathrm{mL}{ }^{-1}$ Spiro-OMeTAD (2,20,7,70-tetrakis ( $N, N$-dip-methoxyphenylamino)-9,90-spirobiftuorene, sublimed grade $99.8 \%$, Borun chemicals) in chlorobenzene was doped with $17.5 \mathrm{~mL}$ Li-TFSI ( $520 \mathrm{mg} \mathrm{mL}^{-1}$ in acetonitrile) and $28.8 \mathrm{~mL} 4$-TBP. The Spiro-OMeTAD layer was spin coated on the perovskite layer with $1200 \mathrm{rpm}$ for $30 \mathrm{~s}$. Finally, $100 \mathrm{~nm}$ Ag layer was deposited on the Spiro-OMeTAD HTL coated substrate by thermal evaporation with an evaporation rate of $2 \AA^{-1}$ under a vacuum condition of $1 \times 10^{-6}$ mbar. The device area was flexed to be $0.045 \mathrm{~cm}^{2}$ with the use of a metal mask. So, the overall device structures were: ITO/ sol-gel $\mathrm{ZnO}$ or $\mathrm{AZO} / \mathrm{MA}_{0.6} \mathrm{FA}_{0.4} \mathrm{PbI}_{3}$ perovskite/Spiro$\mathrm{OMeTAD} / \mathrm{Ag}$.

The current-voltage characteristics of the devices were measured with a NREL calibrated Keithley 2400 Source Meter under $100 \mathrm{~mW} \mathrm{~cm}^{-2}$ (AM 1.5G) simulated sunlight. For optical characterization like transmittance, reflectance and absorbance measurement, a UV-VIS-NIR spectrometer (Perkin Elmer - Lambda 950) was used. X-ray diffraction (XRD) with $\mathrm{CuK} \alpha$ radiation was performed by step-scanning with a step size of $0.02^{\circ}$. Surface topology and device cross sectional view were captured by Carl Zeiss AURIGA Cross Beam SEM (scanning electron microscopy) and the surface roughness was measured with Bruker Dimension ICON SPM AFM (atomic force microscopy) machine. The impedance analysis was conducted with an Autolab PGSTAT-30 equipped with a frequency analyzer module in the frequency range from $1 \mathrm{MHz}$ to $10 \mathrm{~Hz}$. AC oscillating amplitude was as low as $20 \mathrm{mV}$ (RMS) to maintain the linearity of the response. External quantum efficiency measurements were performed using a QEX10 spectral response system from PV Measurements Inc.

\section{Results}

The $\mathrm{MA}_{0.6} \mathrm{FA}_{0.4} \mathrm{PbI}_{3}$ perovskite film was deposited on top of both $\mathrm{ZnO}$ and $\mathrm{AZO}$ films in an identical way using two step dipping method. It was confirmed from the XRD pattern of $\mathrm{MA}_{0.6} \mathrm{FA}_{0.4} \mathrm{PbI}_{3}$ perovskite film that the formations of mixed organic cation perovskite in which both MAI and FAI organic cations have been incorporated in the same lattice frame [9]. The optical properties $\mathrm{MA}_{0.6} \mathrm{FA}_{0.4} \mathrm{PbI}_{3} / \mathrm{ZnO}$ and $\mathrm{MA}_{0.6} \mathrm{FA}_{0.4} \mathrm{PbI}_{3} / \mathrm{AZO}$ films on top of ITO/glass substrates were investigated with absorbance measurement. The absorbance pattern of $\mathrm{MA}_{0.6} \mathrm{FA}_{0.4} \mathrm{PbI}_{3} / \mathrm{ZnO}$ and $\mathrm{MA}_{0.6} \mathrm{FA}_{0.4} \mathrm{PbI}_{3} / \mathrm{AZO}$ films showed the onset for both the films $820 \mathrm{~nm}$ which is similar with the red-shifted spectral response achieved with mixed organic cation perovskite $\left(\mathrm{MA}_{0.6} \mathrm{FA}_{0.4} \mathrm{PbI}_{3}\right)$ compared to mono organic methyl ammonium lead triiodide perovskite $\left(\mathrm{MAPbI}_{3}\right)$, having an absorption onset around $\sim 800 \mathrm{~nm}[10]$. 

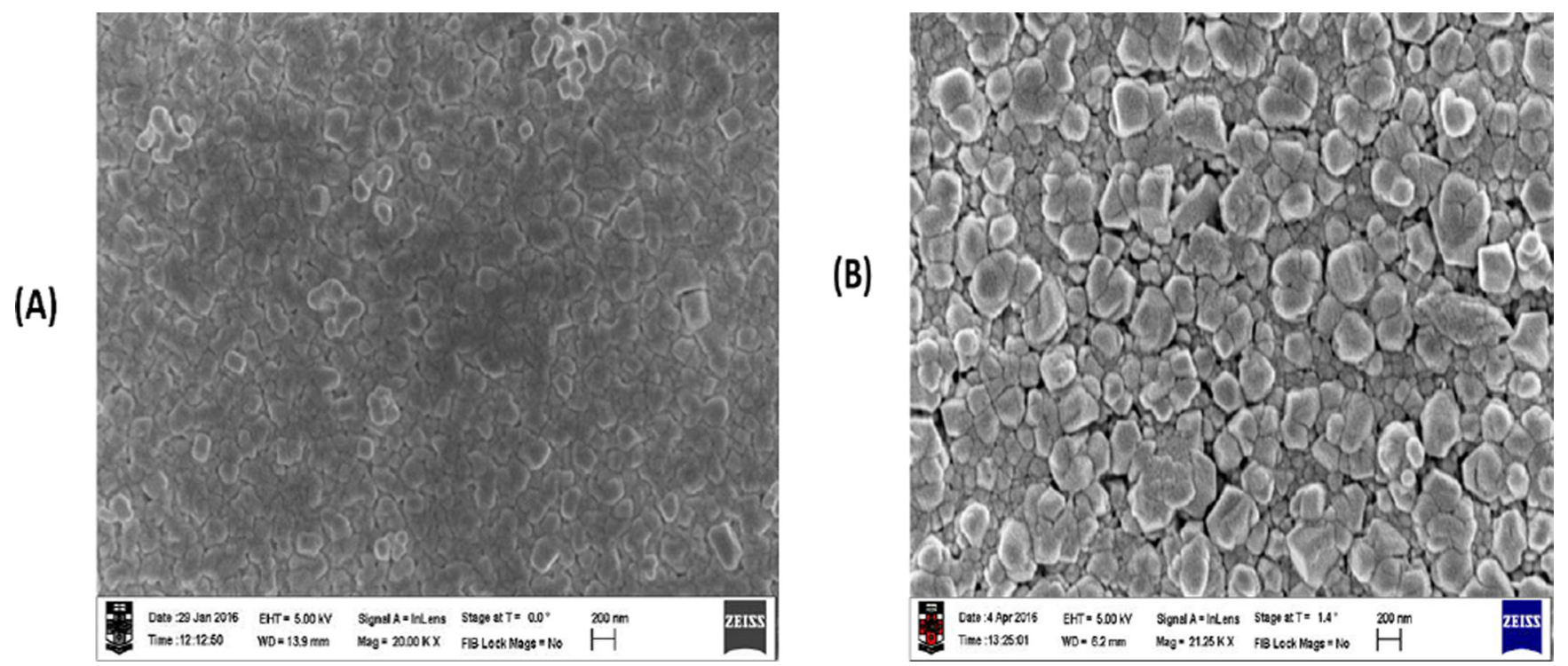

Fig. 1. Surface morphology view (SEM image) of $\mathrm{MA}_{0.6} \mathrm{FA}_{0.4} \mathrm{PbI}_{3}$ perovskite film on top of (A) $\mathrm{ZnO}$ and (B) $\mathrm{Al}$ doped $\mathrm{ZnO}(\mathrm{AZO})$ film.

Figure $1 \mathrm{~A}$ and $\mathrm{B}$ illustrates the SEM surface morphology image of $\mathrm{MA}_{0.6} \mathrm{FA}_{0.4} \mathrm{PbI}_{3} / \mathrm{ZnO}$ and $\mathrm{MA}_{0.6} \mathrm{FA}_{0 \cdot 4} \mathrm{PbI}_{3} /$ AZO films, respectively, on ITO/glass substrate. As observed from Figure 1 the grain size of $\mathrm{MA}_{0.6} \mathrm{FA}_{0.4} \mathrm{PbI}_{3}$ perovskite grown on AZO ETL film is larger compared to that grown on ZnO ETL film. The variation in the surface morphology of identically fabricated perovskite film on different ETL films is similar with the earlier findings that the formation of perovskite film can be significantly modified based on the underlying layer.

The fabricated solar cells performance of $\mathrm{MA}_{0.6} \mathrm{FA}_{0.4} \mathrm{PbI}_{3}$ perovskite absorber with low temperature processed $\mathrm{ZnO}$ and AZO ETLs have been measured. We have investigated the device performance of $\mathrm{MA}_{0.6} \mathrm{FA}_{0.4} \mathrm{PbI}_{3}$ perovskite with pristine $\mathrm{ZnO}$ and different $\mathrm{Al}$ concentration of AZO as ETL. The best performing $\mathrm{MA}_{0 .} \mathrm{FA}_{0.4} \mathrm{PbI}_{3} / \mathrm{AZO}$ device exhibits a $\mathrm{PCE}$ of $16 \%$ with the $J_{\mathrm{SC}}, \quad V_{\mathrm{OC}}$ and $\mathrm{FF}$ value being $20.2 \mathrm{~mA} \mathrm{~cm}^{-2}$, $1014.160 \mathrm{mV}$ and $71 \%$, respectively. Figure 2 shows the $J-V$ curves of the best performing $\mathrm{MA}_{0.6} \mathrm{FA}_{0.4} \mathrm{PbI}_{3} / \mathrm{ZnO}$ and $\mathrm{MA}_{0.6} \mathrm{FA}_{0.4} \mathrm{PbI}_{3} / \mathrm{AZO}$ devices, respectively. The high reproducibility of both the device structures is evident from the statistical histograms (with normal distribution) of PCE, $J_{\mathrm{SC}}, V_{\mathrm{OC}}$ and $\mathrm{FF}$ of 10 identically fabricated $\mathrm{MA}_{0.6} \mathrm{FA}_{0.4} \mathrm{PbI}_{3} / \mathrm{ZnO}$ and $\mathrm{MA}_{0.6} \mathrm{FA}_{0.4} \mathrm{PbI}_{3} / \mathrm{AZO}$ devices.

The average values of $J_{\mathrm{SC}}, V_{\mathrm{OC}}$ and $\mathrm{FF}$ for these devices are $20.18 \mathrm{~mA} \mathrm{~cm}^{-2}, 1004.46 \mathrm{mV}$ and $68.89 \%$, respectively. To the best of our knowledge, the average PCE $14.9 \%$ reported in our study is the highest ever average $\mathrm{PCE}$ attained with $\mathrm{MA}_{0.6} \mathrm{FA}_{0.4} \mathrm{PbI}_{3}$ perovskite device processing at low temperature processed AZO layer. The $\mathrm{MA}_{0.6} \mathrm{FA}_{0.4} \mathrm{PbI}_{3} / \mathrm{ZnO}$ devices demonstrate comparatively lower average PCE of $11.82 \%$ with the average $J_{\mathrm{SC}}, V_{\mathrm{OC}}$ and FF values being $21.44 \mathrm{~mA} \mathrm{~cm}^{-2}, 973.48 \mathrm{mV}^{2}$ and $56.69 \%$, respectively. Even the best performing $\mathrm{MA}_{0.6} \mathrm{FA}_{0.4} \mathrm{PbI}_{3}$ / $\mathrm{ZnO}$ device shows relatively degraded photovoltaic performance (PCE: $13.40 \%, J_{\mathrm{SC}}: 22.39 \mathrm{~mA} \mathrm{~cm}^{-2}, V_{\mathrm{OC}}: 984.24 \mathrm{mV}$ and FF: $60.66 \%$ ) in contrast with the average performance exhibited by $\mathrm{MA}_{0.6} \mathrm{FA}_{0.4} \mathrm{PbI}_{3} / \mathrm{AZO}$ devices.
Our un-encapsulated $\quad \mathrm{MA}_{0.6} \mathrm{FA}_{0.4} \mathrm{PbI}_{3} / \mathrm{ZnO}$ and $\mathrm{MA}_{0.6} \mathrm{FA}_{0.4} \mathrm{PbI}_{3} / \mathrm{AZO}$ samples were stored for 30 days in a $\mathrm{N}_{2}$ filled glovebox following the protocols mentioned in earlier perovskite degradation studies under dark and device performance was evaluated at regular intervals at humidity controlled (35-40\% relative humidity) ambience at room temperature. We measured the $J-V$ curves of $\mathrm{MA}_{0.6} \mathrm{FA}_{0.4} \mathrm{PbI}_{3} / \mathrm{ZnO}$ and $\mathrm{MA}_{0.6} \mathrm{FA}_{0.4} \mathrm{PbI}_{3} / \mathrm{AZO}$ devices, respectively, throughout the time period of degradation study (30 days) with certain intervals as shown in Figure 3. The highest PCE for AZO or ZnO ETL based devices can be obtained after 4-5 days, which is consistent with the identical trend reported in previous perovskite literatures [11].

To understand the reasons behind the device stability with $\mathrm{MA}_{0.6} \mathrm{FA}_{0.4} \mathrm{PbI}_{3} / \mathrm{AZO}$ devices, we have conducted impedance characterization of 30 day-aged $\mathrm{MA}_{0.6} \mathrm{FA}_{0.4} \mathrm{PbI}_{3} / \mathrm{ZnO}$ and $\mathrm{MA}_{0.6} \mathrm{FA}_{0.4} \mathrm{PbI}_{3} / \mathrm{AZO}$ devices. The fitted values of various electronic parameters using equivalent circuit model we have estimated the contact resistance for both samples. Since, the HTL layer (SpiroOMeTAD in both cases) remains constant for both the device structures, the variation in device contact resistance can be attributed to the disparity in degradation phenomena of the ETL layers ( $\mathrm{ZnO}$ and $\mathrm{AZO})$ and their concomitant influence on the decomposition of neighbouring $\mathrm{MA}_{0.6} \mathrm{FA}_{0.4} \mathrm{PbI}_{3}$ perovskite film.

Reduced interface trapping phenomena in $\mathrm{MA}_{0.6} \mathrm{FA}_{0.4} \mathrm{PbI}_{3} / \mathrm{AZO}$ devices can be attributed to the reduced perovskite grain boundary aided by large grain atop AZO film and trap state filling in AZO associated with Burstein-Moss effect [12]. Subdued interfacial trapping endows with suppressed recombination phenomenon in aged $\mathrm{MA}_{0.6} \mathrm{FA}_{0.4} \mathrm{PbI}_{3} / \mathrm{AZO}$ devices which is also congruent with $95 \%$ higher recombination resistance compared to $\mathrm{MA}_{0.6} \mathrm{FA}_{0.4} \mathrm{PbI}_{3} / \mathrm{ZnO}$ devices as shown in Figure 4. The higher recombination and shunt resistance in aged $\mathrm{MA}_{0.6} \mathrm{FA}_{0.4} \mathrm{PbI}_{3} / \mathrm{AZO}$ devices contribute to their higher $V_{\mathrm{OC}}$ value which leads to enhanced device stability in contrast with $\mathrm{MA}_{0.6} \mathrm{FA}_{0.4} \mathrm{PbI}_{3} / \mathrm{ZnO}$ devices. 


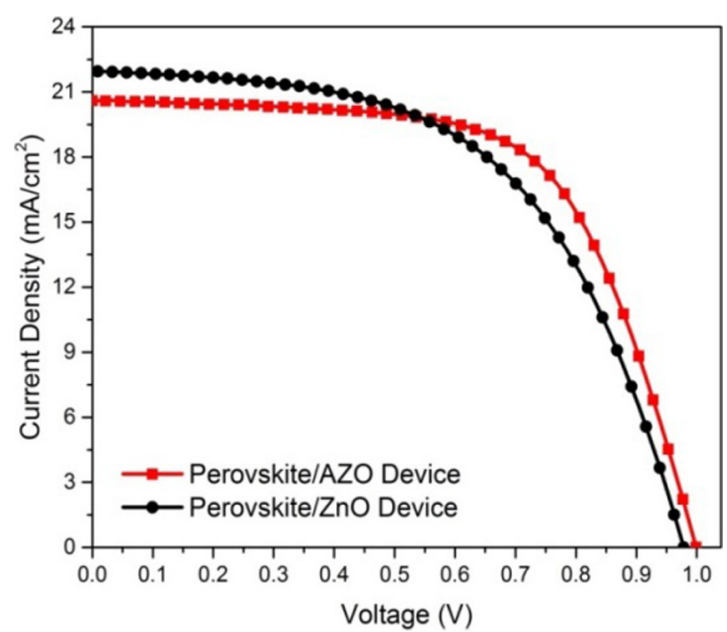

Fig. 2. $J-V$ characteristics of $\mathrm{MA}_{0.6} \mathrm{FA}_{0.4} \mathrm{PbI}_{3}$ perovskite $/ \mathrm{ZnO}$ and $\mathrm{MA}_{0.6} \mathrm{FA}_{0.4} \mathrm{PbI}_{3}$ perovskite/AZO devices at room temperature.

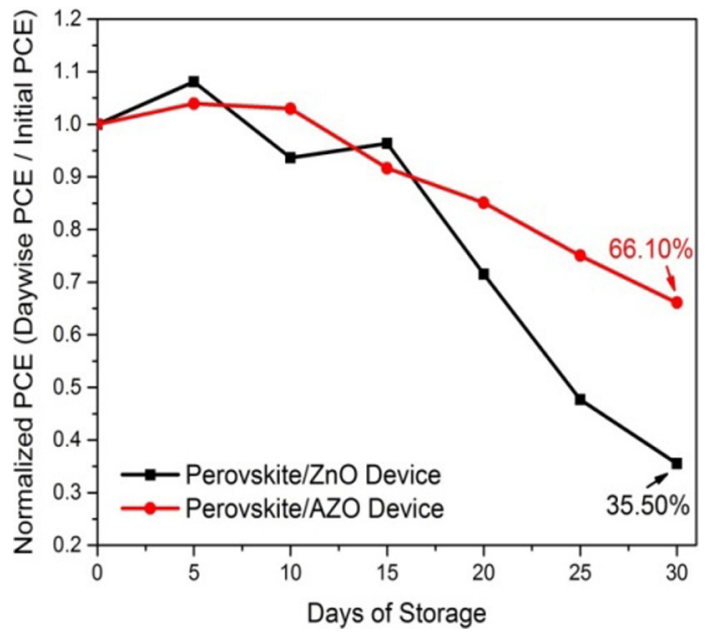

Fig. 3. 30 Days normalized $\mathrm{PCE}$ of $\mathrm{MA}_{0.6} \mathrm{FA}_{0.4} \mathrm{PbI}_{3} / \mathrm{ZnO}$ and $\mathrm{MA}_{0.6} \mathrm{FA}_{0.4} \mathrm{PbI}_{3} / \mathrm{AZO}$ devices attained from a systematic stability study. $\mathrm{MA}_{0.6} \mathrm{FA}_{0.4} \mathrm{PbI}_{3} / \mathrm{AZO}$ devices retain higher normalized PCE compared to $\mathrm{MA}_{0.6} \mathrm{FA}_{0.4} \mathrm{PbI}_{3} / \mathrm{ZnO}$ devices.

\section{Discussion}

Boyen et al. [13] has reported that the interparticle connectivity of perovskite grain and its surface morphology can be enhanced by the removal of residual impurities from the underneath metal oxide ETL. It has already been reported that the residual impurities like hydroxyl $\left(\mathrm{OH}^{-}\right)$ ions and organic $\mathrm{CH}_{3} \mathrm{COO}^{-}$radicals are significantly reduced in $\mathrm{Al}$ dopant incorporated $\mathrm{ZnO}$ film compared to pristine $\mathrm{ZnO}$ film. The larger grain size of $\mathrm{MA}_{0.6} \mathrm{FA}_{0.4} \mathrm{PbI}_{3}$ perovskite grown on AZO ETL film can be attributed to the enhanced interparticle connectivity of perovskite owing to the significantly reduced residual impurity [14] at the underneath AZO film. From the statistical quantity analysis of AFM images, the RMS surface roughness of $\mathrm{MA}_{0.6} \mathrm{FA}_{0.4} \mathrm{PbI}_{3} / \mathrm{AZO}$ film $(55.7 \mathrm{~nm})$ has been found to be lower than that $(56.80 \mathrm{~nm})$ of $\mathrm{MA}_{0.6} \mathrm{FA}_{0.4} \mathrm{PbI}_{3} / \mathrm{ZnO}$ film [9].

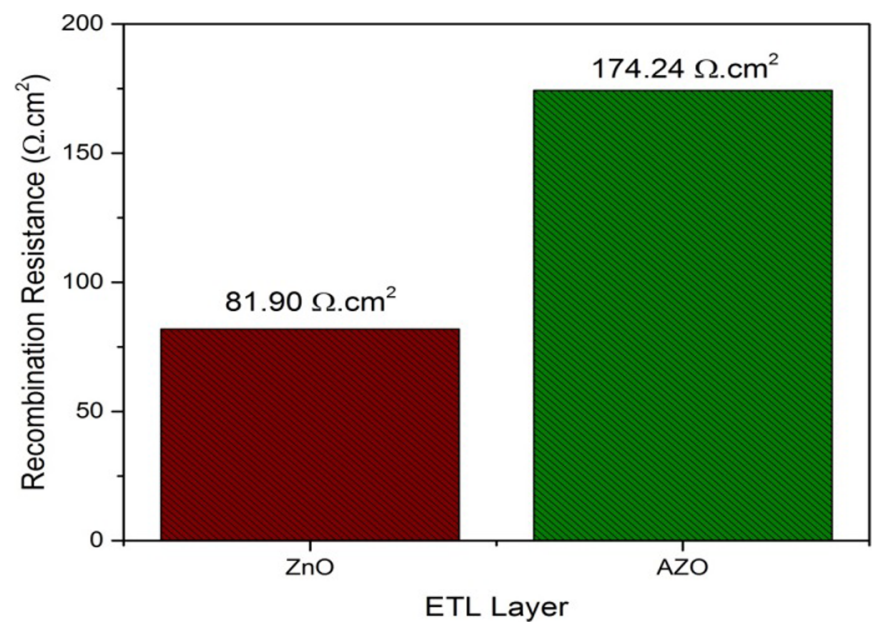

Fig. 4. Recombination resistance (fitted data from impedance spectroscopy at $0.9 \mathrm{~V}$ under dark) of $\mathrm{MA}_{0.6} \mathrm{FA}_{0.4} \mathrm{PbI}_{3}$ perovskite devices containing $\mathrm{ZnO}$ and $\mathrm{AZO}$ ( $\mathrm{Al}$ doped $\mathrm{ZnO}$ ) ETL.

The initial rise in PCE of devices in Figure 3 can be attributed to the substantial rise in $\mathrm{FF}$ value which is related to the oxidation of Spiro-OMeTAD HTL in ambient condition for improved hole conductivity and thus more efficient charge extraction. As comprehended from Figure 3, $\mathrm{MA}_{0.6} \mathrm{FA}_{0.4} \mathrm{PbI}_{3} / \mathrm{AZO}$ devices retain nearly $70 \%$ of their initial PCE even after 1 month, whereas for $\mathrm{MA}_{0.6} \mathrm{FA}_{0.4} \mathrm{PbI}_{3} / \mathrm{ZnO}, \mathrm{PCE}$ drops down to $36 \%$ of the commencing $\mathrm{PCE}$ during the same time range which denotes nearly two times higher stability with $\mathrm{MA}_{0.6} \mathrm{FA}_{0.4} \mathrm{PbI}_{3} / \mathrm{AZO}$ devices. As observed in Figure 3, about two-fold enhancement in device stability with $\mathrm{MA}_{0.6} \mathrm{FA}_{0.4} \mathrm{PbI}_{3} / \mathrm{AZO}$ devices originates from two times higher $J_{\mathrm{SC}}$ and about $8 \%$ higher $V_{\mathrm{OC}}$ values retained in $\mathrm{MA}_{0.6} \mathrm{FA}_{0.4} \mathrm{PbI}_{3} / \mathrm{AZO}$ devices compared to $\mathrm{MA}_{0.6} \mathrm{FA}_{0.4} \mathrm{PbI}_{3} / \mathrm{ZnO}$ in course of 1 month long degradation study. In general, perovskite film decomposes rapidly in the presence of water vapour [15]. Since, $\mathrm{ZnO}$ film is hygroscopic, it traps water at its surface [16] and with aging, $\mathrm{ZnO}$ becomes saturated with moisture. Due to the more hydrophobic nature of AZO film, the trapped moisture-assisted perovskite decomposition rate is expected to be lower in $\mathrm{MA}_{0.6} \mathrm{FA}_{0.4} \mathrm{PbI}_{3} / \mathrm{AZO}$ devices, which explicates higher $J_{\mathrm{SC}}$ and lower contact resistance retained in the $\mathrm{MA}_{0.6} \mathrm{FA}_{0.4} \mathrm{PbI}_{3} / \mathrm{AZO}$ devices which eventually lead to their higher stability compared to $\mathrm{MA}_{0.6} \mathrm{FA}_{0.4} \mathrm{PbI}_{3} / \mathrm{ZnO}$ devices. In an aged perovskite device, small voids present in Spiro-OMeTAD HTL film trigger the migration of $\mathrm{CH}_{3} \mathrm{NH}_{3} \mathrm{I}$ ion through them to react with silver cathode and produce $\mathrm{AgI}$ (silver iodide) which results in the decomposition in perovskite layer [17].

The large grain size and concomitant reduction in $\mathrm{MA}_{0.6} \mathrm{FA}_{0.4} \mathrm{PbI}_{3}$ perovskite grain boundary overlying the AZO layer ensure superior charge transfer across the interface thereby lowering the donor-acceptor pair recombination and significantly suppressing current leakage phenomena, which correlate to their efficient charge extraction and enhanced fill factor. The enhanced flatband potential coupled with high recombination resistance 
from impedance measurement explains the larger open circuit voltage observed in $\mathrm{MA}_{0.6} \mathrm{FA}_{0.4} \mathrm{PbI}_{3} / \mathrm{AZO}$ devices and its implication on high PCE [9].

In summary, we have reported a highly efficient $(\sim 16 \%)$ mixed organic cation based pure triiodide $\left(\mathrm{MA}_{0.6} \mathrm{FA}_{0.4} \mathrm{PbI}_{3}\right)$ perovskite device fabricated with a low temperature processed AZO ETL in a planar device structure. The present work demonstrates simultaneous enhancement in device performance and stability in PSCs fortified with low hysteresis and opens up a new research pathway towards the fabrication of less energy extensive, flexible substrate compatible, efficient PSCs exhibiting superior device performance, stability and reduced photocurrent hysteresis behaviour for reliable operation aimed at long term practical applications.

The authors gratefully acknowledge the financial support provided by Future Solar Technologies Pty. Ltd. for this research work. The authors would also like to acknowledge the endless support from the staffs of Photovoltaic and Renewable Energy Engineering School, Electron Microscope Unit (EMU) and Solid State and Elemental Analysis Unit under Mark Wainwright Analytical Centre, UNSW.

\section{References}

1. P.-W. Liang, C.-Y. Liao, C.-C. Chueh, F. Zuo, S.T. Williams, X.-K. Xin, J. Lin, A.K.Y. Jen, Adv. Mater. 26, 3748 (2014)

2. NREL, Photovoltaics efficiency chart, 2016, http://www. nrel.gov/ncpv/images/efficiency_chart.jpg
3. Y. Zhou, M. Yang, W. Wu, A.L. Vasiliev, K. Zhu, N.P. Padture, J. Mater. Chem. A 3, 8178 (2015)

4. J. Yang, B.D. Siempelkamp, E. Mosconi, F. De Angelis, T.L. Kelly, Chem. Mater. 27, 4229 (2015)

5. N.J. Jeon, J.H. Noh, W.S. Yang, Y.C. Kim, S. Ryu, J. Seo, S. I. Seok, Nature 517, 476 (2015)

6. T.M. Koh, K. Fu, Y. Fang, S. Chen, T.C. Sum, N. Mathews, S.G. Mhaisalkar, P.P. Boix, T. Baikie, J. Phys. Chem. C 118, $16458(2014)$

7. S. Aharon, A. Dymshits, A. Rotem, L. Etgar, J. Mater. Chem. A 3, 9171 (2015)

8. N. Pellet, P. Gao, G. Gregori, T.-Y. Yang, M.K. Nazeeruddin, J. Maier, M. Grätzel, Angew. Chem. Int. Ed. 53, 3151 (2014)

9. M.A. Mahmud, N.K. Elumalai, M.B. Upama, D. Wang, M. Wright, T. Sun, C. Xu, F. Haque, A. Uddin, RSC Adv. 6, 86108 (2016)

10. D. Liu, T.L. Kelly, Nat. Photon. 8, 133 (2014)

11. J. You, L. Meng, T.-B. Song, T.-F. Guo, Y. Yang, W.-H. Chang, Z. Hong, H. Chen, H. Zhou, Q. Chen, Y. Liu, N. De Marco, Y. Yang, Nat. Nanotechnol. 11, 75 (2015)

12. A. Aprilia, P. Wulandari, V. Suendo, H. Herman, R. Hidayat, A. Fujii, M. Ozaki, Sol. Energy Mater. Sol. Cells 111, 181 (2013)

13. B. Conings, L. Baeten, T. Jacobs, R. Dera, J. D'Haen, J. Manca, H.-G. Boyen, APL Mater. 2, 81505 (2014)

14. T. Salim, S. Sun, Y. Abe, A. Krishna, A.C. Grimsdale, Y.M. Lam, J. Mater. Chem. A 3, 8943 (2015)

15. J. Yang, B.D. Siempelkamp, D. Liu, T.L. Kelly, ACS Nano 9, $1955(2015)$

16. Y. Sun, J.H. Seo, C.J. Takacs, J. Seifter, A.J. Heeger, Adv. Mater. 23, 1679 (2011)

17. Y. Kato, L.K. Ono, M.V. Lee, S. Wang, S.R. Raga, Y. Qi, Adv. Mater. Interfaces 2, 1500195 (2015)

Cite this article as: Ashraf Uddin, Md Arafat Mahmud, Naveen Kumar Elumalai, Dian Wang, Mushfika Baishakhi Upama, Matthew Wright, Kah Howe Chan, Faiazul Haque, Cheng Xu, Perovskite solar cells for roll-to-roll fabrication, Renew. Energy Environ. Sustain. 2, 7 (2017) 